\title{
Impact of gravity wave drag on the thermospheric circulation: implementation of a nonlinear gravity wave parameterization in a whole-atmosphere model
}

\author{
Yasunobu Miyoshi ${ }^{1}$ and Erdal Yiğit ${ }^{2}$ \\ ${ }^{1}$ Department of Earth and Planetary Sciences, Kyushu University, Fukuoka, Japan \\ ${ }^{2}$ Space Weather Laboratory, Department of Physics and Astronomy, George Mason University, Fairfax, VA, USA
}

Correspondence: Yasunobu Miyoshi (y.miyoshi.527@m.kyushu-u.ac.jp)

Received: 8 March 2019 - Discussion started: 25 March 2019

Revised: 5 August 2019 - Accepted: 19 September 2019 - Published: 17 October 2019

\begin{abstract}
To investigate the effects of the gravity wave (GW) drag on the general circulation in the thermosphere, a nonlinear GW parameterization that estimates the GW drag in the whole-atmosphere system is implemented in a wholeatmosphere general circulation model (GCM). Comparing the simulation results obtained with the whole-atmosphere scheme with the ones obtained with a conventional linear scheme, we study the GW effects on the thermospheric dynamics for solstice conditions. The GW drag significantly decelerates the mean zonal wind in the thermosphere. The GWs attenuate the migrating semidiurnal solar-tide (SW2) amplitude in the lower thermosphere and modify the latitudinal structure of the SW2 above a $150 \mathrm{~km}$ height. The SW2 simulated by the GCM based on the nonlinear wholeatmosphere scheme agrees well with the observed SW2. The GW drag in the lower thermosphere has zonal wavenumber 2 and semidiurnal variation, while the GW drag above a $150 \mathrm{~km}$ height is enhanced in high latitude. The GW drag in the thermosphere is a significant dynamical factor and plays an important role in the momentum budget of the thermosphere. Therefore, a GW parameterization accounting for thermospheric processes is essential for coarse-grid wholeatmosphere GCMs in order to more realistically simulate the atmosphere-ionosphere system.
\end{abstract}

\section{Introduction}

It has been widely recognized that internal atmospheric waves from the lower atmosphere, such as planetary waves, solar tides, and gravity waves (GWs), propagate into the upper atmosphere and affect the circulation in the thermosphere-ionosphere system (Yiğit and Medvedev, 2015, and references therein). In this study, we focus our attention on the impact of GWs of lower-atmospheric origin on the thermospheric circulation and solar tides. While middle-atmospheric effects of GWs have been extensively studied, GW effects in the upper atmosphere above the turbopause have been studied to a much lesser extent due to a combination of observational and modeling challenges. On one hand, due to insufficient observations of the neutral winds in the thermosphere, the behavior of GWs in the thermosphere has not been sufficiently known. On the other hand, whole-atmosphere models, which can study GW propagation continuously in different layers of the atmosphere, has been developed only in recent times. Middle-atmosphere models had upper boundaries somewhere in the upper mesosphere, while thermosphere-ionosphere models had lower boundaries around the lower thermosphere. Additionally, the vast majority of the existing GWs focused on the middleatmosphere dynamics and thus were not designed to represent GW processes in the upper atmosphere. Developments and challenges in the parameterization of gravity waves in the whole-atmosphere region have been discussed in detail in the work by Yiğit and Medvedev (2013). Briefly, gravity waves propagating from the lower atmosphere into the thermosphere are subject to additional dissipation processes that 
are characteristic of the thermosphere-ionosphere system, as documented for the first time in the context of a parameterization in the work by Yiğit et al. (2008). These wavedamping mechanisms are molecular diffusion and thermal conduction and ion drag in addition to nonlinear interactions. Therefore, in order to realistically simulate GW dynamics in the thermosphere, these processes have to be taken into account. The majority of the conventional GW schemes were not designed for the upper atmosphere in the first place.

Recently, an increasing number of numerical studies have revealed direct upward propagation of GWs from the lower atmosphere into the thermosphere and demonstrated significant GW effects on the thermospheric circulation (e.g., Yiğit et al., 2014; Heale et al., 2014; Gavrilov and Kshevetskii, 2015). Earlier, using a regional model and ray-tracing method, Vadas and Fritts (2004) showed that GWs generated by cumulus convection can propagate into the thermosphere and produce large GW drag in the thermosphere. GWs with high frequency (large vertical wavelength) can penetrate into the thermosphere (Vadas and Fritts, 2005). Yiğit et al. (2008) developed a nonlinear whole-atmosphere GW parameterization and succeeded in the implementation and application of their GW parameterization in the Coupled Middle Atmosphere Thermosphere-2 (CMAT2) general circulation model (GCM). Yiğit et al. (2009) showed that the dynamical effects of gravity waves in the thermosphere are comparable with the ion-drag effects up to ionospheric F2-region altitudes. Later, based on the similar modeling framework, Yiğit and Medvedev (2009) showed for the first time that GW thermal effects are very important globally in the thermosphere, competing with joule heating, and ultimately cool the thermosphere. More recently, Yiğit and Medvedev (2017) demonstrated that the small-scale GWs impact the amplitude of the diurnal tide in the low-latitude middle atmosphere and in the high-latitude thermosphere. Using the first-generation CMAT model with two different older GW parameterizations, England et al. (2006) investigated effects of the GW drag on the diurnal tide and green-line airglow emissions during equinox in the equatorial mesosphere and lower thermosphere (MLT). Based on idealized numerical simulations with the Yiğit et al. (2008) scheme, Medvedev et al. (2017) have discovered that the magnetic field configuration can significantly influence the propagation and dissipation of loweratmospheric GWs in the thermosphere via the ion-drag force.

GW effects can also be studied using high-resolution GCMs. Models are increasingly capable of implementing higher resolutions, which can capture smaller-scale physics. Using a GW-resolving (i.e., high horizontal resolution) GCM, Miyoshi and Fujiwara (2008) and Miyoshi et al. $(2014,2015)$ investigated upward propagation of GWs and the GW drag in the thermosphere. They indicated that the GW drag in the thermosphere is much larger than that in the mesopause region. The GW activity in the thermosphere is stronger in winter than in summer and is correlated with the strength of the strato-mesospheric jet. Using a GW-resolving
Whole Atmosphere Community Climate Model (WACCM), Liu et al. (2014) also studied upward propagation of GWs excited by tropical convection up to a $105 \mathrm{~km}$ height. Overall, high-resolution simulations supported the finding that the mean GW effects in the thermosphere can be adequately represented by physics-based GW parameterizations, such as the one developed in the work by Yiğit et al. (2008).

Previous numerical studies indicated that the GW drag plays an important role in maintaining the momentum and energy balance in the thermosphere. Both GW parameterizations and high-resolution simulations provide various advantages as well as some limitations. While the mean global structure of GW effects is well represented by GW parameterizations extending into the thermosphere, high-resolution simulations can more self-consistently simulate GW processes probably in more detail; for example, smaller-scale variability in GWs can be better captured. This implies overall that a GW-resolving GCM is necessary in order to simulate thermospheric circulation more accurately. However, numerical diffusion schemes (e.g., hyperdiffusivity) may excessively damp smaller-scale GWs. Often, GW sources and their generations are still parameterized in high-resolution simulations. Also, conducting numerical simulations with a GWresolving GCM requires high-performance computer systems and overall needs much more computational time and data storage. Therefore, long-term simulations using a GWresolving GCM are unpractical. Therefore, a low-resolution GCM based on a physics-based whole-atmosphere GW parameterization is strongly required. However, there are only a few studies concerning GW drag parameterization for the thermosphere, and there are various aspects of GW effects in the thermosphere that are still unexplored. One such unexplored territory that is the focus of this paper is the interaction of GWs with the semidiurnal migrating tide (SW2) in the upper atmosphere. Simultaneously, this work serves as the first study with the whole-atmosphere GCM by Miyoshi and Fujiwara (2003) implementing the whole-atmosphere GW parameterization by Yiğit et al. (2008). Thus, we will also study and revisit the mean GW effects on the thermosphere and solar tides.

The descriptions of the GCM, the GW parameterization, and numerical simulations are presented in Sect. 2. Results and discussions are presented in Sect. 3. Concluding remarks follow in Sect. 4.

\section{General circulation model, gravity wave schemes, and experiment design}

The model used in this study is a whole-atmosphere GCM as shown in Miyoshi (2006) and Miyoshi and Fujiwara (2003, 2008). This model is a thermospheric extension of the middle-atmosphere model developed at Kyushu University (Miyahara et al., 1993; Miyoshi, 1999). The GCM is a global spectral model with a horizontal grid spacing of $2.8^{\circ}$ lati- 
tude $\times 2.8^{\circ}$ longitude. The GCM has 150 layers, with a vertical resolution of 0.2 -scale heights. The GCM covers the region from the ground to the exobase. It has a complete set of physical processes appropriate for the whole-atmosphere region. The GCM is the same as the neutral atmospheric part of an atmosphere-ionosphere coupled model, GAIA (Groundto-topside model of Atmosphere and Ionosphere for Aeronomy; Jin et al., 2008, 2012).

The GCM incorporates schemes for a hydrological cycle, a boundary layer, moist convection, and infrared and solar radiations (Miyoshi and Fujiwara, 2003; Miyoshi, 2006). Effects of mountains and land-sea contrast are also taken into account. The GCM was nudged by Japanese Meteorological Agency reanalysis data (JRA-55; Kobayashi et al., 2015) up to a $40 \mathrm{~km}$ height to simulate realistic temporal variations in the lower atmosphere (Jin et al., 2012). In the thermosphere, the GCM has schemes for molecular diffusion, thermal conductivity, joule heating, ion-drag force, and auroral precipitation heating. To estimate joule heating, ion-drag force, and auroral precipitation heating, the electron density is prescribed using an empirical ionosphere model. The global electron density distribution produced by the solar radiation is represented by Chiu's empirical model (Chiu, 1975). Electrons produced by auroral particles are estimated by FullerRowell and Evans (1987). We use a coarse grid in this study, which provides computational efficiency, and represent GWs that are not explicitly resolved by the model with orographic and nonorographic GW parameterizations. The GW parameterization developed by McFarlane (1987) is used for orographic GWs. The previous standard version of the GCM includes a linear nonorographic GW parameterization developed by Lindzen (1981). However, the GW drag estimated by these GW parameterizations is taken into account only below a $100 \mathrm{~km}$ height. Thus, note that no GW effects are calculated in the thermosphere above a $100 \mathrm{~km}$ height in this configuration. This setup mimics the traditional approach of accounting for GWs only in the middle atmosphere, which is essentially what low-top middle-atmosphere models used to do. The numerical simulation using this original GCM is called EXP1. This standard version is described in detail in previous publications (Miyoshi and Fujiwara, 2003; Miyoshi, 2006; Miyoshi et al., 2009).

To assess impacts of GW drag on the general circulation in the thermosphere as well as in the lower and middle atmosphere, we need a GW scheme that extends into the thermosphere. Therefore, the GW parameterization developed in the work by Yiğit et al. (2008) has been implemented in the GCM developed by Miyoshi and Fujiwara (2003). Yiğit's GW parameterization can estimate the GW effects in the whole-atmosphere system from the troposphere to the upper thermosphere. The GW spectrum is specified in terms of momentum fluxes as a function of horizontal phase speeds. The phase speeds of GWs used in GW calculations range from 2 to $80 \mathrm{~m} \mathrm{~s}^{-1}$. The peak GW flux at the source level and the horizontal wavenumber are set at $0.00025 \mathrm{~m}^{2} \mathrm{~s}^{-2}$ and $2 \pi / 250 \mathrm{~km}^{-1}$, respectively (see Fig. 1 of Yiğit et al., 2012, for a representative GW spectrum). The GW spectrum adopted in this study and its relation to the observation were discussed in detail in Yiğit et al. (2008). Dissipation of gravity waves due to nonlinear interactions (Medvedev and Klaassen, 2000), radiative damping, molecular diffusion and thermal conduction, eddy viscosity, and ion drag are taken into account. This scheme has been used successfully in different Earth-modeling frameworks (e.g., Lübken et al., 2018) and also for Mars' atmosphere (Yiğit et al., 2018). The numerical simulation with Yiğit's whole-atmosphere parameterization is called EXP2. The GCM used in EXP1 is identical to the GCM used in EXP2 except for the nonorographic GW parameterization. Namely, in EXP2, Lindzen's GW parameterization, which cuts off GW effects at around $100 \mathrm{~km}$, is replaced by Yiğit's GW parameterization, which calculates GW effects in the entire atmosphere. By comparing EXP1 and EXP2, we investigate the impact of the GW drag on the general circulation in the middle and upper atmospheres by comparing EXP1 and EXP2.

To exclude influences from temporal variations in solar UV and EUV fluxes and geomagnetic activity, we performed the numerical simulations under solar minimum and geomagnetically quiet conditions. The $10.7 \mathrm{~cm}$ solar radio flux (F10.7) was fixed at $70 \times 10^{-22} \mathrm{~W} \mathrm{~m}^{-2} \mathrm{~Hz}^{-1}$, and the crosspolar potential was set at $30 \mathrm{kV}$ during the numerical simulations. Numerical simulations were conducted under June solstice conditions. Numerical simulation started on 1 June (year 2015), and a 2-year numerical integration with seasonal variation was performed. The time step of the GCM is $30 \mathrm{~s}$, and the GW drag is estimated at each time step. The data are sampled every $1 \mathrm{~h}$ during the numerical simulation. The data from 1 to 30 June in the second year (year 2016) are analyzed in this study.

\section{Results and discussions}

\subsection{Zonal-mean fields}

Impacts of GWs on the zonal-mean zonal wind are examined first. Figure 1a shows the height-latitude section of the zonal-mean and diurnal-mean zonal wind obtained by the application of the Lindzen scheme (EXP1). Data are averaged from 1 to 30 June. Note that thermospheric GW effects above a $100 \mathrm{~km}$ height are not incorporated in this scheme. Strong jets exist in the stratosphere and mesosphere. These jets weaken in the upper mesosphere, and the reversal of the zonal-wind direction occurs at around a $80-100 \mathrm{~km}$ height. It is well known that this reversal of the zonal wind is generated by the GW drag (e.g., Lindzen, 1981; Matsuno, 1982; Garcia and Solomon, 1985). Again, the westward and eastward wind appear above a $120 \mathrm{~km}$ height in the Northern Hemisphere (NH) and Southern Hemisphere (SH), respectively. The peak of the westward wind $\left(48-52 \mathrm{~m} \mathrm{~s}^{-1}\right)$ above $120 \mathrm{~km}$ 
is located at $50^{\circ} \mathrm{N}$, whereas the peak of the eastward wind $\left(20-25 \mathrm{~m} \mathrm{~s}^{-1}\right)$ above a $120 \mathrm{~km}$ height appears at $30^{\circ} \mathrm{S}$.

Figure $1 \mathrm{~b}$ shows the zonal and diurnal-mean zonal-wind distribution obtained by the application of the Yiğit scheme (EXP2). As shown before, Yiğit's GW parameterization is implemented in the whole-atmosphere region. The stratomesospheric jets weaken in the upper mesosphere, and the reversal of the zonal-wind direction occurs at a $80-100 \mathrm{~km}$ height. The difference of the zonal-mean zonal wind between EXP2 and EXP1 is shown in Fig. 1c. There are substantial differences of the magnitudes of the strato-mesospheric jets between EXP1 and EXP2. The eastward jet in the SH is stronger in EXP1 than in EXP2. On the other hand, the westward jet in the $\mathrm{NH}$ at $20-50^{\circ} \mathrm{N}$ is stronger in EXP1 than in EXP2 by $\sim 22 \mathrm{~m} \mathrm{~s}^{-1}$, and the westward jet poleward of $50^{\circ} \mathrm{N}$ is weaker in EXP1 than in EXP2 by $\sim 8 \mathrm{~m} \mathrm{~s}^{-1}$. These differences of the strength of the jets are mainly caused by the differences of the GW drag distributions, as shown later (Sect. 3.4). Above a $120 \mathrm{~km}$ height, the westward and eastward winds are dominant in the $\mathrm{NH}$ and $\mathrm{SH}$, respectively. These features obtained in EXP2 are the same as those in EXP1. However, the reversal of the zonal-wind direction at a $80-100 \mathrm{~km}$ height is much clearer in EXP2 than in EXP1. The peak values of the zonal-mean zonal wind above a $120 \mathrm{~km}$ height are weaker in EXP2 than in EXP1. These results indicate that including $\mathrm{GW}$ effects above a $100 \mathrm{~km}$ height affects the magnitude of the zonal-mean zonal wind and provides a deceleration mechanism.

Figure 2a and $\mathrm{b}$ show the height-latitude distribution of the zonal-mean meridional wind obtained by EXP1 and EXP2, respectively. In both experiments, southward flow from the summer pole to winter pole is dominant at a $50-100 \mathrm{~km}$ height, whereas northward flow appears between a 100 and $120 \mathrm{~km}$ height. These flows are stronger in EXP2 than in EXP1, which is explained by the enhanced GW drag in EXP2 as shown later. Above a $130 \mathrm{~km}$ height, southward flow is dominant in both experiments. The magnitude of the southward wind between a 130 and $250 \mathrm{~km}$ height is weaker in EXP2 than that in EXP1 except for southward of $30^{\circ} \mathrm{S}$ (Fig. 3c). This weaker meridional wind in EXP2 is caused by the meridional component of the GW drag. On the other hand, the difference of meridional wind between EXP1 and EXP2 is small above a $250 \mathrm{~km}$ height (less than $10 \%$ ).

Figure $3 \mathrm{a}$ and $\mathrm{b}$ show the height-latitude distribution of the zonal-mean temperature obtained by EXP1 and EXP2, respectively. At a $80-100 \mathrm{~km}$ height, Cooling and warming occur at $30-90^{\circ} \mathrm{N}$ and at $60-90^{\circ} \mathrm{S}$, respectively (Fig. 3c). This cooling and warming is caused by the enhanced southward wind (meridional circulation) at a $80-100 \mathrm{~km}$ height in EXP2. Namely, the cooling (warming) at $30-90^{\circ} \mathrm{N}(60-$ $90^{\circ} \mathrm{S}$ ) is due to enhanced upward (downward) wind. It is noteworthy that cooling prevails above a $100 \mathrm{~km}$ height. In particular, cooling at high latitudes in the $\mathrm{NH}$ exceeds $60 \mathrm{~K}$. This cooling is caused by the GW thermal effect. This indicates that GW-induced cooling also affects thermal structure in the upper thermosphere. Our results support the conclusion of the GCM work by Yiğit and Medvedev (2013), who showed for the first time that GWs cool the thermosphere during low solar-activity conditions.

\subsection{Migrating semidiurnal tide}

The impact on the migrating semidiurnal tide (SW2) is examined here. Figure 4a shows the height-latitude distribution of the temperature component of the SW2 amplitude in June obtained by EXP1. The amplitude maximizes at around a $125 \mathrm{~km}$ height. The maxima are $41 \mathrm{~K}$ at $15^{\circ} \mathrm{S}$ and $38 \mathrm{~K}$ at $20^{\circ} \mathrm{N}$. The peak of the SW2 amplitude above a $200 \mathrm{~km}$ height $(34 \mathrm{~K})$ appears at $15-25^{\circ} \mathrm{S}$, and the secondary peak $(10 \mathrm{~K})$ is found around $45^{\circ} \mathrm{N}$. Using the SABER (Sounding of the Atmosphere using Broadband Emission Radiometry) measurement aboard the TIMED (Thermosphere Ionosphere Mesosphere Energetics Dynamics) satellite, Pancheva and Mukhtarov (2011) studied climatology (6-year mean from 2002 to 2007) of SW2 temperature tide observation. Figure 2.3 in Pancheva and Mukhtarov (2011) indicates that the SW2 in June at a $110 \mathrm{~km}$ height has peaks at $15-30^{\circ} \mathrm{N}$ and $15-25^{\circ} \mathrm{S}$. The maxima at $15-30^{\circ} \mathrm{N}$ and at $15-25^{\circ} \mathrm{S}$ are $25-28$ and $15-20 \mathrm{~K}$, respectively. The peak values at a $110 \mathrm{~km}$ height in EXP1 are about $30-35 \mathrm{~K}$, which is much larger than the observation. Forbes et al. (2011) investigated seasonal variation in the SW2 in the exobase (about 400$500 \mathrm{~km}$ ) using the CHAMP (CHAllenging Minisatellite Payload) and GRACE (Gravity Recovery and Climate Experiment) accelerometer measurements. The observed SW2 in June also has two peaks $\left(15-20^{\circ} \mathrm{S}\right.$ and $\left.40^{\circ} \mathrm{N}\right)$, and the peak value during the solar minimum is $24 \mathrm{~K}$ (Figs. 7 and 8 of Forbes et al., 2011). The simulated SW2 in the SH (NH) is larger (smaller) than the observed SW2.

Figure $4 \mathrm{~b}$ shows the temperature component of the SW2 amplitude obtained by EXP2. The SW2 in the lower thermosphere maximizes at $15-20^{\circ} \mathrm{S}$ and at $20^{\circ} \mathrm{N}$. The peak values of the monthly mean SW2 amplitude in EXP2 at a $110 \mathrm{~km}$ height are $26 \mathrm{~K}$ at $20^{\circ} \mathrm{N}$ and $21 \mathrm{~K}$ at $15^{\circ} \mathrm{S}$. The SW2 peaks at a $100-200 \mathrm{~km}$ height move southward in EXP2. The SW2 amplitude in the lower thermosphere in EXP2 is weaker than the one in EXP1 by about $20 \%-40 \%$ (Fig. 4c). Results obtained with EXP2 compare better with the observed SW2 amplitude. Above a $200 \mathrm{~km}$ height, the SW2 amplitude in EXP2 maximizes at $10^{\circ} \mathrm{S}(25 \mathrm{~K})$, and the secondary peak is found at $40^{\circ} \mathrm{N}(15-20 \mathrm{~K})$. The SW2 amplitude in the SH $(\mathrm{NH})$ is weaker (stronger) in EXP2 than in EXP1. This means that the latitudinal structure of the SW2 above a $200 \mathrm{~km}$ height is modified by GW propagating and dissipation in the middle and upper thermosphere. Moreover, the SW2 in the upper thermosphere obtained by EXP2 agrees well with the observed SW2 amplitude.

Figure 5a and $\mathrm{b}$ show the zonal-wind component of the SW2 amplitude in EXP1 and EXP2, respectively. Figure 5c shows the amplitude difference between EXP1 and EXP2. 

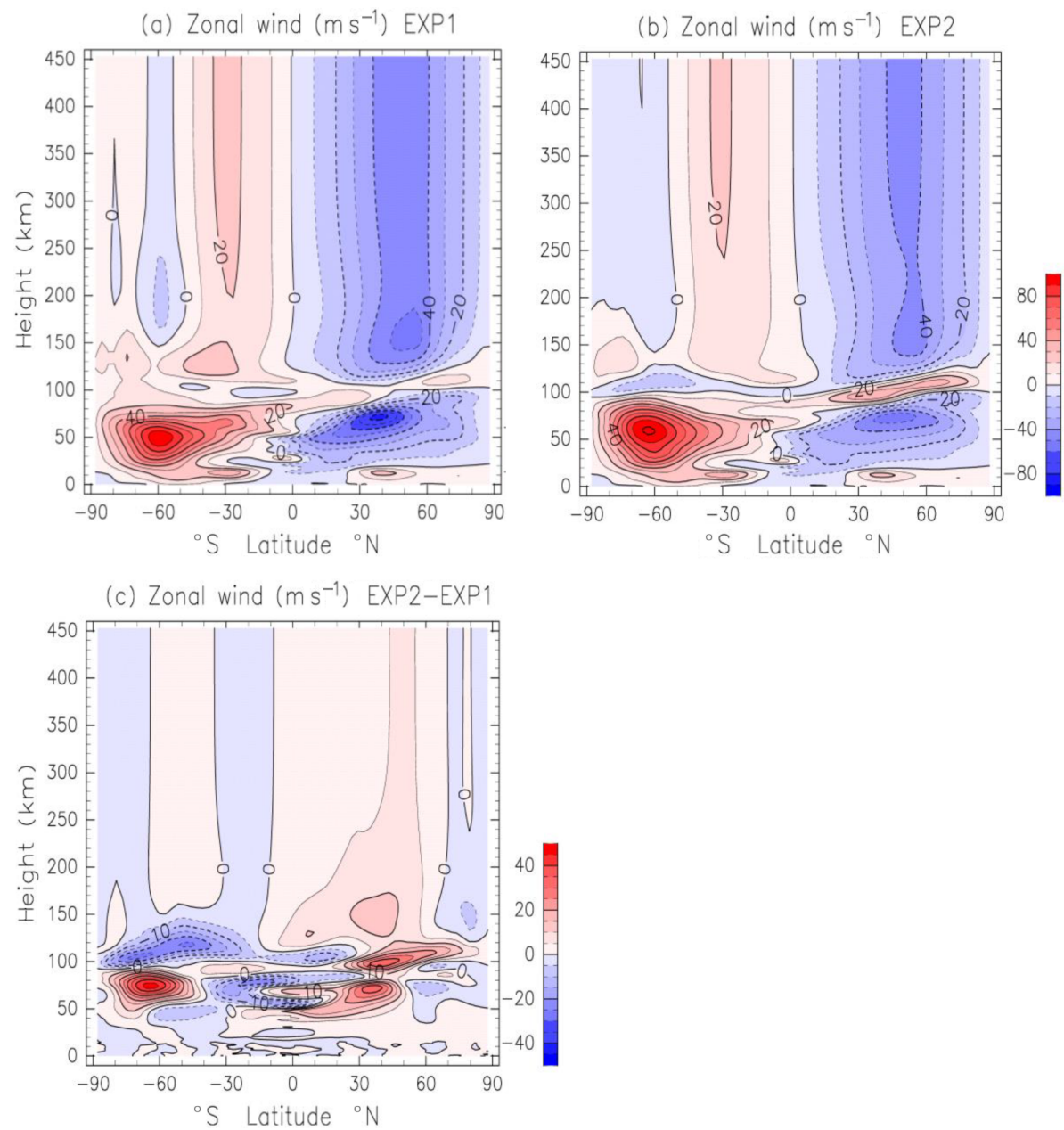

Figure 1. (a) Height-latitude section of zonal and diurnal-mean zonal wind obtained by EXP1 (the application of the Lindzen scheme below $100 \mathrm{~km}$ height). Data are averaged from 1 to 30 June. Contour intervals of black lines are $10 \mathrm{~m} \mathrm{~s}^{-1}$. Negative and positive values are eastward and westward winds, respectively. (b) As in (a) except for the application of the Yiğit scheme in the whole atmosphere (EXP2). (c) Difference of the zonal wind between EXP1 and EXP2 (EXP2-EXP1). Contour intervals are $5 \mathrm{~m} \mathrm{~s}^{-1}$.

The maximum of the zonal-wind component of the SW2 at a $120 \mathrm{~km}$ height in EXP1 (EXP2) is $68 \mathrm{~m} \mathrm{~s}^{-1}\left(55 \mathrm{~m} \mathrm{~s}^{-1}\right)$. The GW parameterization attenuates the zonal-wind component of the SW2 in the lower thermosphere. Moreover, above a $200 \mathrm{~km}$ height, the GW parameterization modifies the latitudinal structure of the zonal-wind component. The effects of the GW drag on the migrating diurnal tide in the MLT was studied by Miyahara and Forbes (1991). They showed that the DW1 is attenuated by the GW drag. Yiğit and Medvedev (2017) investigated the effects of GWs on the diurnal tide from the mesosphere to the upper thermosphere. They found that while GWs enhance the tidal amplitude in the MLT, GWs can both damp and strengthen the tides in the thermosphere. The impact on DW1 obtained in this study is similar to that in Yiğit and Medvedev. On the other hand, the present results indicate that the GW drag has wide-reaching implications for the migrating tides. Namely GWs attenuate the SW2 amplitude in the MLT, improving model simula- tions with respect to observations. Overall, this is the most dominant effect of the GW drag on the SW2.

The SW2 also has significant day-to-day variations. For example, the SW2 amplitude at $20^{\circ} \mathrm{N}$ in EXP1 ranges from 27 to $37 \mathrm{~K}$, whereas the SW2 amplitude in EXP2 ranges from 22 to $31 \mathrm{~K}$. The standard deviation of day-to-day variations in the SW2 amplitude at $20^{\circ} \mathrm{N}$ in EXP1 and EXP2 is 2.8 and $2.9 \mathrm{~K}$, respectively. Similar day-to-day variations in the SW2 amplitude are found below a $100 \mathrm{~km}$ height. These results indicate that day-to-day variations in the SW2 amplitude are primarily generated in the lower atmosphere and propagate into the lower thermosphere.

\subsection{Migrating terdiurnal tide}

Figure 6a shows the height-latitude distribution of the temperature component of the migrating terdiurnal tide (TW3) amplitude in June obtained by EXP1. The amplitude peak is 

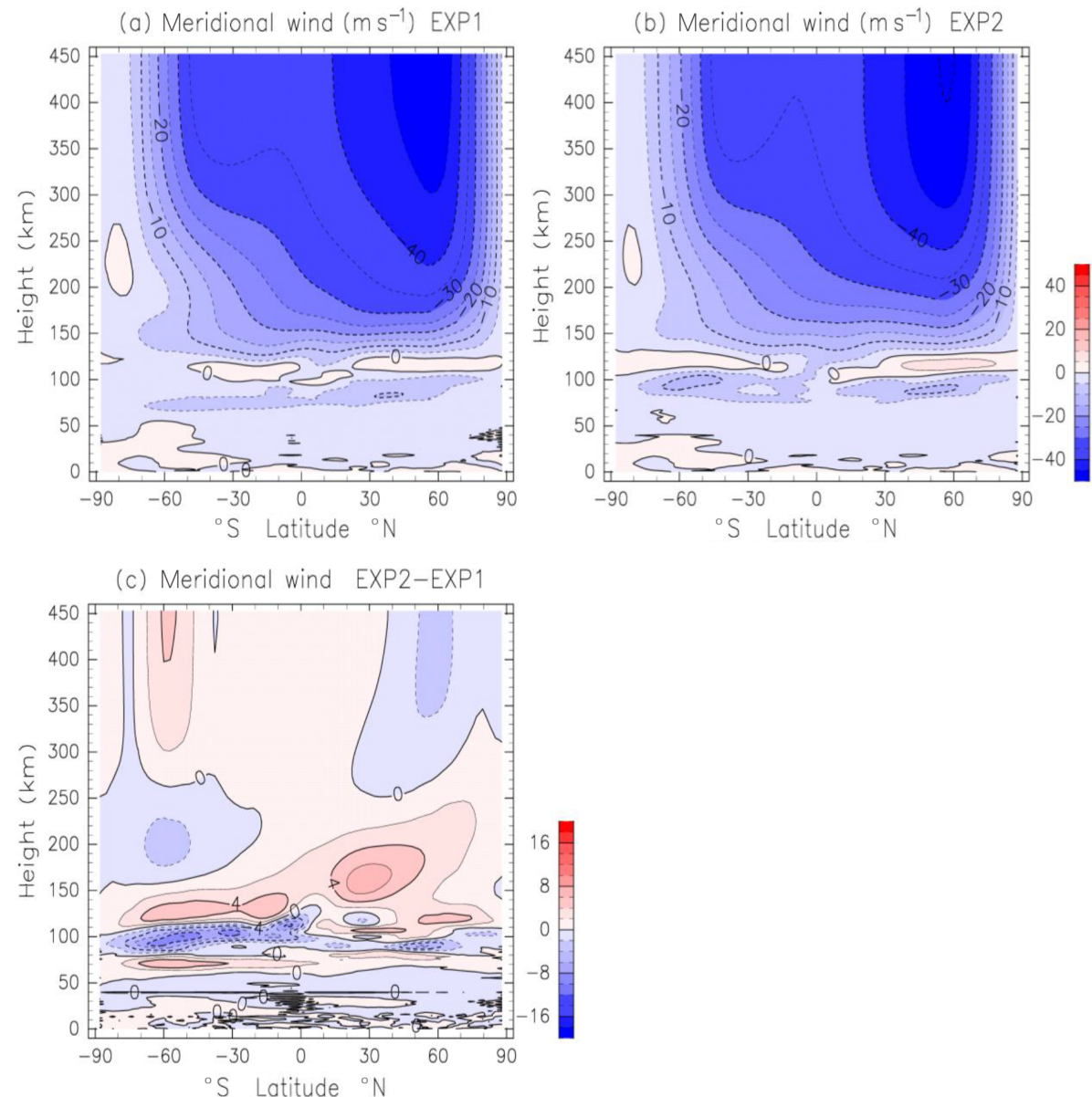

Figure 2. (a) Zonal-mean meridional wind obtained by EXP1 (Lindzen's parameterization below $100 \mathrm{~km}$ height). Data are averaged from 1 to 30 June. Negative and positive values are southward and northward wind, respectively. Contour intervals are $5 \mathrm{~m} \mathrm{~s}{ }^{-1}$. (b) As in (a) except for EXP2 (Yiğit's parameterization in the whole atmosphere). (c) Meridional wind difference between EXP1 and EXP2 (EXP2-EXP1). Contour intervals are $2 \mathrm{~m} \mathrm{~s}^{-1}$.

located at $15^{\circ} \mathrm{N}$ latitude, and the secondary peak appears at $25-30^{\circ} \mathrm{S}$. The maxima are $23 \mathrm{~K}$ at $15^{\circ} \mathrm{N}$ and a $130 \mathrm{~km}$ height and $18 \mathrm{~K}$ at $17.5^{\circ} \mathrm{S}$ and a $165 \mathrm{~km}$ height. Figure $6 \mathrm{~b}$ shows the temperature component of the TW3 amplitude obtained by EXP2, and Fig. 6c shows the amplitude difference between EXP1 and EXP2. The latitudinal structure of the TW3 in EXP2 is quite similar to that in EXP1. However, the amplitude is weaker in EXP2 than in EXP1 by about $20 \%-40 \%$. The amplitude difference is significant in the $120-220 \mathrm{~km}$ height range. The TW3 is also attenuated by the GW drag. Forbes et al. (2008) indicated that the TW3 amplitude at a $110 \mathrm{~km}$ height is between 5 and $8 \mathrm{~K}$. However, there are few studies concerning the satellite observation of TW3 amplitude in the 120-220 km height range. A detailed comparison of the TW3 amplitude between the simulation and observation is a subject of a future study.

\subsection{Zonal mean of the zonal GW drag}

Figure 7a shows the height-latitude section of the zonal and diurnal mean of the zonal GW drag estimated by Lindzen's parameterization (EXP1). Eastward (westward) acceleration exists in the $\mathrm{NH}(\mathrm{SH})$ and attenuates the mesospheric jet. Figure $7 \mathrm{~b}$ shows the zonal and diurnal mean of the zonal GW drag estimated by Yiğit's parameterization (EXP2). The differences of the GW drag below a $100 \mathrm{~km}$ height are substantial. The magnitude of the GW drag in EXP1 below a $100 \mathrm{~km}$ height is similar to that in EXP2. However, the peak of the GW drag in EXP1 is located around $60-70 \mathrm{~km}$, whereas that in EXP2 is located around a $90-100 \mathrm{~km}$ height. These differences of the GW drag below a $100 \mathrm{~km}$ height produce the differences of the strato-mesospheric jets. The GW drag in EXP2 extends to a $300 \mathrm{~km}$ height. It is noteworthy that the magnitude of the GW drag in a $150-300 \mathrm{~km}$ height is comparable to that in the MLT. 
(a) Temperature (K) EXP1

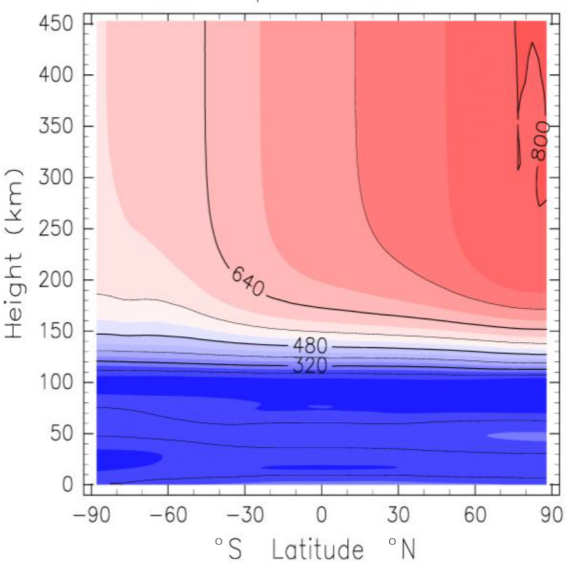

(c) Temperature (K) EXP2-EXP1

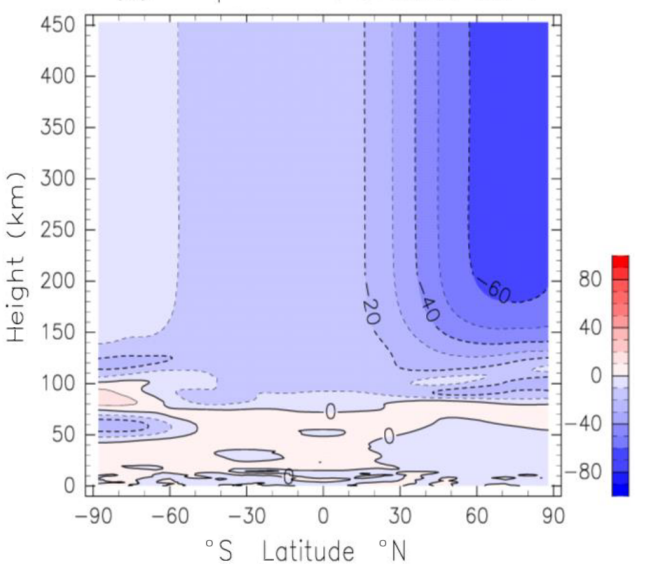

(b) Temperature (K) EXP2

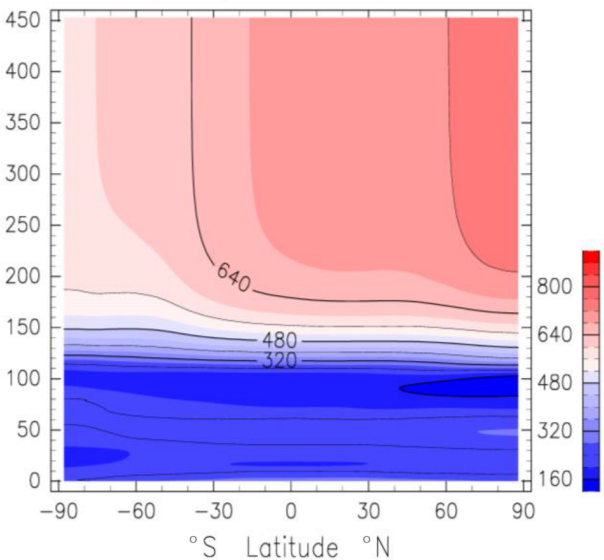

Figure 3. (a) Zonal-mean temperature obtained by EXP1 (Lindzen's parameterization below $100 \mathrm{~km}$ height). Data are averaged from 1 to 30 June. Units are kelvins. (b) As in (a) except for EXP2 (Yiğit's parameterization in the whole atmosphere). (c) Temperature difference between EXP1 and EXP2 (EXP2-EXP1). Contour intervals are $10 \mathrm{~K}$.

\subsection{Longitudinal variation in the $\mathrm{GW}$ drag at $35^{\circ} \mathrm{N}$}

In the previous sections, we investigate zonal and diurnal mean of the GW drag. Longitudinal and diurnal variabilities in the winds are significant in the thermosphere, so longitudinal and diurnal variability of the GW drag is examined next. Figure 8a shows the height-longitude distribution of the zonal GW drag at $35^{\circ} \mathrm{N}$, where the SW2 amplitude maximizes in the lower thermosphere. The zonal GW drag in Fig. 8a is averaged between 00:00 and 01:00 UT. The GW drag at a $70-100 \mathrm{~km}$ height is eastward at all longitudes and contributes the attenuation and reversal of the westward jet in the upper mesosphere.

The zonal and diurnal mean of the zonal GW drag at $35^{\circ} \mathrm{N}$ in the $100-200 \mathrm{~km}$ height region is smaller than $20 \mathrm{~m} \mathrm{~s}^{-1} \mathrm{~d}^{-1}$ (Fig. 7b). However, Fig. 8a indicates that the GW drag can range from -100 to $200 \mathrm{~m} \mathrm{~s}^{-1} \mathrm{~d}^{-1}$ within the $1 \mathrm{~d}$ period. The maximum acceleration is located at $157^{\circ} \mathrm{E}$ and a $150 \mathrm{~km}$ height. The GW drag has a zonal wavenumber 2 structure in the $100-200 \mathrm{~km}$ height region, and the peak of the GW drag descends with increasing longitude. Figure $8 \mathrm{~b}$ shows a height-longitude section of the zonal wind at $35^{\circ} \mathrm{N}$ averaged between 00:00 and 01:00 UT. The zonal-wind distribution in the $100-200 \mathrm{~km}$ height region has also zonal wavenumber 2 structure and descends with increasing longitude, indicating characteristics of the upward-propagating SW2. The eastward (westward) acceleration of GW drag in the 100-200 km region occurs in the region of westward (eastward) wind. It is clearly seen that the GW drag attenuates the zonal-wind variation associated with the SW2. Thus, the attenuation of the SW2 in EXP2 is explained by dissipating GWs as represented by the Yiğit scheme. The main dissipation mechanisms of GWs in the thermosphere are due to ion drag, molecular diffusion, and thermal conduction, while in the MLT nonlinear interactions play an important role.

Figure $9 \mathrm{a}$ and $\mathrm{b}$ show the global distribution of the zonal GW drag at $120 \mathrm{~km}$ at two representative times, 00:00-01:00 and 06:00-07:00 UT, respectively. The GW drag in low and middle latitudes has zonal wavenumber 2 structure. The magnitude of the GW drag sometimes exceeds $150 \mathrm{~m} \mathrm{~s}^{-1} \mathrm{~d}^{-1}$. 

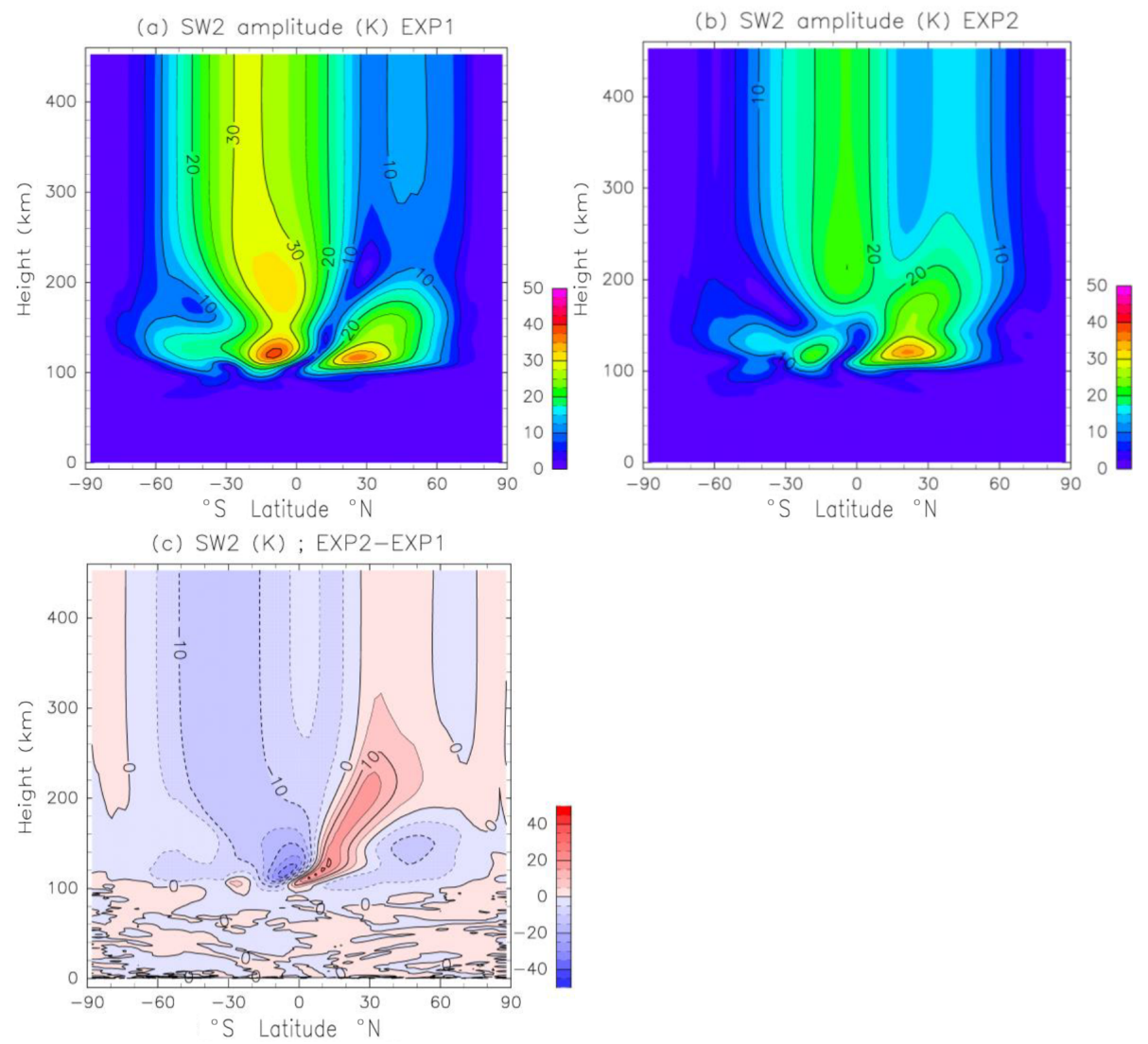

Figure 4. (a) Height-latitude distribution of the temperature component of the SW2 amplitude in June obtained by EXP1. Units are kelvins. Contour intervals are 5 K. (b) As in (a) except for EXP2. (c) Temperature difference between EXP1 and EXP2 (EXP2-EXP1).

The distribution of GW drag in 00:00-01:00 UT is clearly out of phase with that in 06:00-07:00 UT, indicating semidiurnal variation in the $\mathrm{GW}$ drag. In the work by Miyoshi et al. (2014), the relationship between GW drag and SW2 was investigated using a GW-resolving GCM. They showed that the semidiurnal variation in the GW drag is significant in the lower thermosphere, and it decelerates the background zonalwind variation. The present result is consistent with the result obtained by Miyoshi et al. (2014).

\subsection{Longitudinal variation in the GW drag at high latitudes}

In this section, the relationship between the GW drag and the zonal wind in high latitudes, where the diurnal variation of the zonal wind is the largest, is investigated. Figure 10a shows the height-longitude section of the zonal GW drag in EXP2 at $65^{\circ} \mathrm{N}$ in 00:00-01:00 UT. Eastward acceleration is dominant in the $60-110 \mathrm{~km}$ height region, which attenuates the westward wind. Above a $150 \mathrm{~km}$ height, zonal wavenumber 1 structure is dominant. Eastward acceleration (westward acceleration) appears in the $0-180^{\circ} \mathrm{E}\left(180-360^{\circ} \mathrm{E}\right)$ longitude sector. Studying the GW drag together with the zonalwind (EXP2) distribution shown in Fig. 10b shows that the
GW drag is predominantly directed against the zonal wind and thus tends to decelerate the wind. It is noteworthy that the magnitude of eastward acceleration at a 130-270 km height is a few hundred meters per second per day, and the maximum values of $-650 \mathrm{~m} \mathrm{~s}^{-1} \mathrm{~d}^{-1}$ is found at $275^{\circ} \mathrm{E}$ and a $230 \mathrm{~km}$ height.

To investigate the impact of the GW drag on the zonalwind variation, the zonal-wind distribution obtained by EXP1 is shown in Fig. 10c. In EXP1, the westward (eastward) wind prevails in the $0-180^{\circ}\left(180-360^{\circ}\right)$ longitude sector above a $150 \mathrm{~km}$ height. Figure $10 \mathrm{~d}$ shows the difference of the zonal wind between EXP2 and EXP1 (EXP2-EXP1). This essentially shows the difference between the impact of the GW effects on the zonal circulation represented by two different schemes. It is noteworthy that the differences are substantial not only above $100 \mathrm{~km}$, where EXP1 does not include any GW drag, but also in the mesosphere. Both the westward and eastward wind above a $150 \mathrm{~km}$ height are 10 $30 \mathrm{~m} \mathrm{~s}^{-1}$ smaller in EXP2 than in EXP1. This means that the GW drag attenuates the amplitude of the wave number 1 structure of the zonal wind. The difference of the zonal wind in the mesosphere is mainly caused by the substantial differ- 
(b) SW2 amplitude $\left(\mathrm{ms}^{-1}\right)$ EXP1

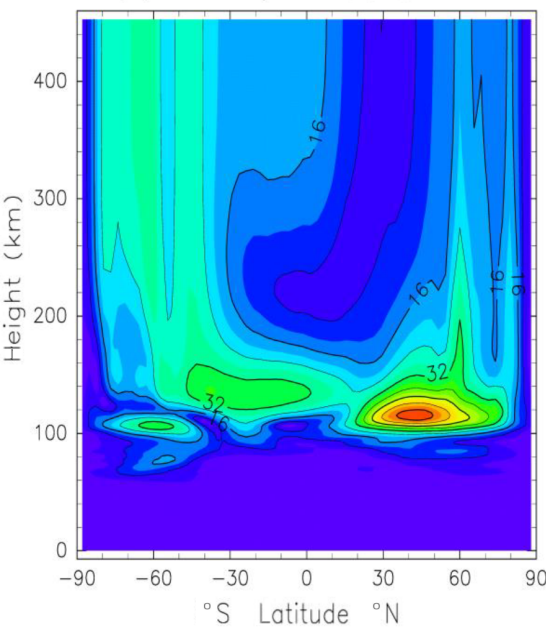

(c) SW2 $\left(\mathrm{ms}^{-1}\right)$; EXP2-EXP1

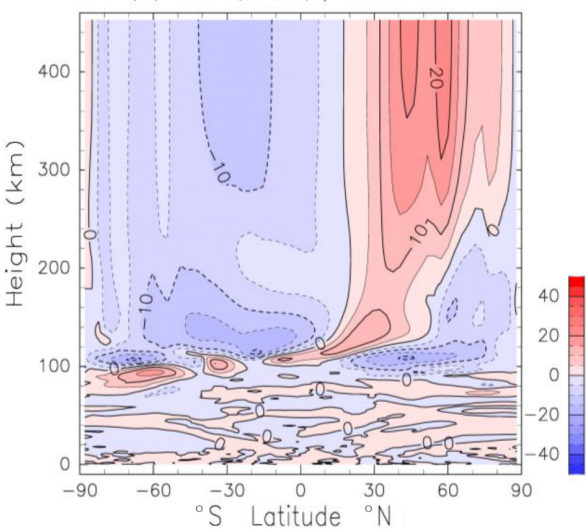

(b) SW2 amplitude $\left(\mathrm{ms}^{-1}\right)$ EXP2

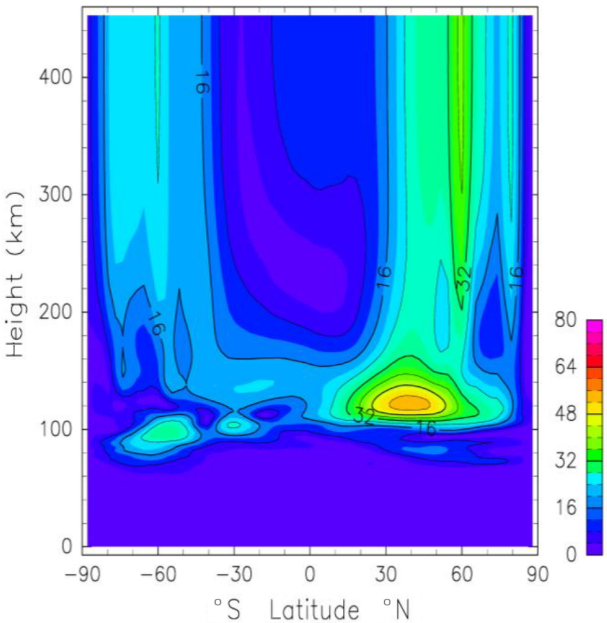

Figure 5. (a) Height-latitude distribution of the zonal-wind component of the SW2 amplitude in June obtained by EXP1. Units are meters per second. (b) As in (a) except for EXP2. (c) Zonal-wind difference between EXP1 and EXP2 (EXP2-EXP1).

ences of the treatment of the GW process. These differences will be discussed in Sect. 3.7.

The global distribution of the zonal GW drag at a $200 \mathrm{~km}$ height is examined here. Figure $11 \mathrm{a}$ and $\mathrm{b}$ show the zonal GW drag distribution in 00:00-01:00 and 06:00-07:00 UT, respectively. In both figures, the $\mathrm{GW}$ drag is significant at high latitudes. For example, in 00:00-01:00 UT, westward acceleration of $1500 \mathrm{~m} \mathrm{~s}^{-1} \mathrm{~d}^{-1}$ is found at $40-50^{\circ} \mathrm{E}$ and $80^{\circ} \mathrm{N}$, while eastward acceleration of $-1200 \mathrm{~m} \mathrm{~s}^{-1} \mathrm{~d}^{-1}$ appears at $275^{\circ} \mathrm{E}$ and $70^{\circ} \mathrm{N}$. These strong $\mathrm{GW}$ drag regions move westward with time, and westward acceleration of $-1200 \mathrm{~m} \mathrm{~s}^{-1} \mathrm{~d}^{-1}$ appears at $170^{\circ} \mathrm{E}$ and $80^{\circ} \mathrm{N}$ in $06: 00$ 07:00 UT. The magnitude of the GW drag in high latitudes is comparable to the magnitude of the ion-drag force (e.g., Yiğit et al., 2012; Miyoshi et al., 2014).

Figure $11 \mathrm{c}$ and $\mathrm{d}$ show the horizontal wind distribution at a $200 \mathrm{~km}$ height in 00:00-01:00 and 06:00-07:00 UT, respectively. Colored shading in Fig. 11a and b shows the zonalwind distribution. The enhanced zonal GW drag is located at the regions where the strong zonal wind appears. The strong zonal winds in high latitudes are mainly generated by the convective electric fields of magnetospheric origin, auroral energy precipitation, and ion-neutral coupling processes such as ion-drag force and joule heating (e.g., Yiğit and Ridley, 2011). The enhanced eastward (westward) wind is favorable for upward propagation of westward-moving (eastwardmoving) GWs from the lower atmosphere. The westward (eastward) acceleration due to the dissipation and/or breaking of westward-moving (eastward-moving) GWs occurs in the eastward (westward) wind region. This is the reason why the GW drag is enhanced at high latitudes. These results indicated that the GW drag plays an important role in the momentum budget in high latitudes at around a $200 \mathrm{~km}$ height. Using a GW-resolving GCM, Miyoshi et al. (2014) showed the enhancement of the GW drag in the polar region at a $200 \mathrm{~km}$ height. Their result is in good agreement with the results presented here. 
(a) TW3 amplitude (K) EXP1

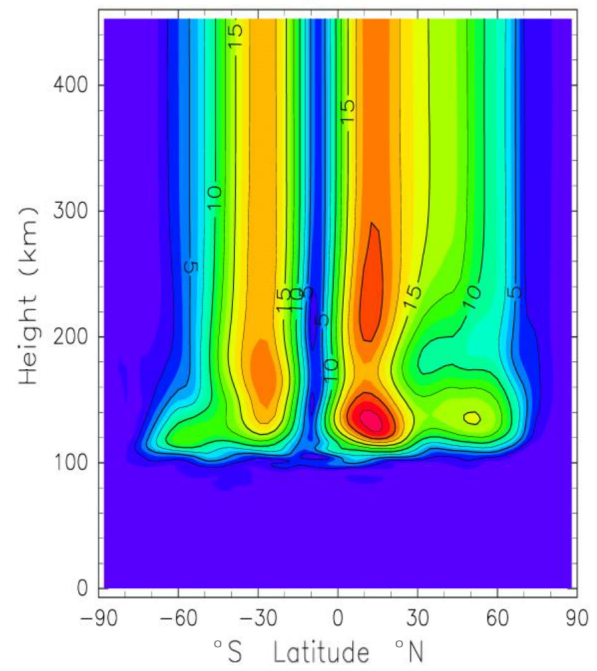

(c) TW3 (K) ; EXP2-EXP1

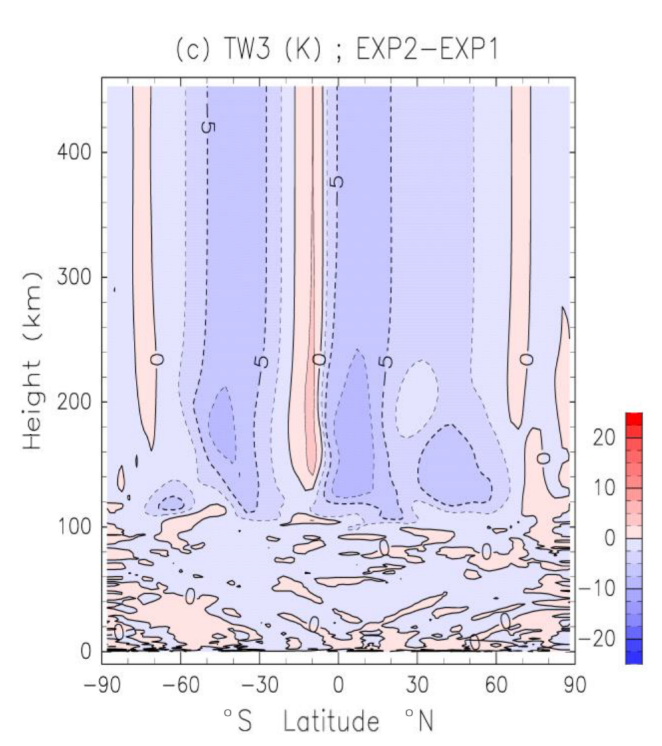

(b) TW3 amplitude (K) EXP2

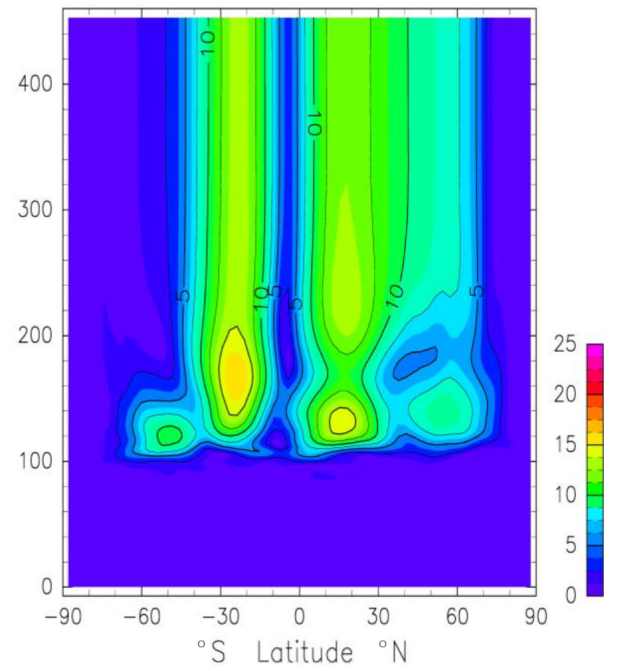

Figure 6. (a) Temperature component of the TW3 amplitude in June obtained by EXP1. Units are kelvins. Contour intervals are 5 K. (b) As in (a) except for EXP2. (c) Temperature difference between EXP1 and EXP2 (EXP2-EXP1). Contour intervals are $2.5 \mathrm{~K}$.

\subsection{Discussions}

General circulation models (GCMs) provide a powerful methodology for studying the global effects of gravity waves (GWs) in the atmosphere. One strength is the continuous coverage of atmospheric layers; thus interaction processes between different layers can be studied. However, they have limited resolutions, so physical parameterizations are crucial. Nowadays, atmospheric models are gradually being converted into whole-atmosphere models, which can provide a framework in which atmospheric wave propagation can be studied from the lower atmosphere to the upper atmosphere in a more self-consistent manner (e.g., Miyoshi and Fujiwara, 2003, 2008; Akmaev et al., 2008). Also, it is increasingly acknowledged that $\mathrm{GW}$ parameterizations must cover the entire atmosphere, following the realization that GWs deposit their energy and momentum at different layers in the atmosphere, with a significant portion being deposited in the middle thermosphere. In this context, we exploit the capability of the whole-atmosphere GW parameterization of Yiğit et al. (2008). Note that recent studies showed that lower-atmospheric GWs can directly propagate into the thermosphere and can dump significant energy and momentum there. For example, the magnitude of the GW drag in the lower thermosphere sometimes exceeds $150 \mathrm{~m} \mathrm{~s}^{-1} \mathrm{~d}^{-1}$, whereas the magnitude of the GW drag at a $200 \mathrm{~km}$ height at high latitudes exceeds $1000 \mathrm{~m} \mathrm{~s}^{-1} \mathrm{~d}^{-1}$. In summary, GWs can produce a variety of effects in the thermosphere, including dynamical (Yiğit et al., 2009), thermal (Yiğit and Medvedev, 2009; Hickey et al., 2011), and mixing effects 

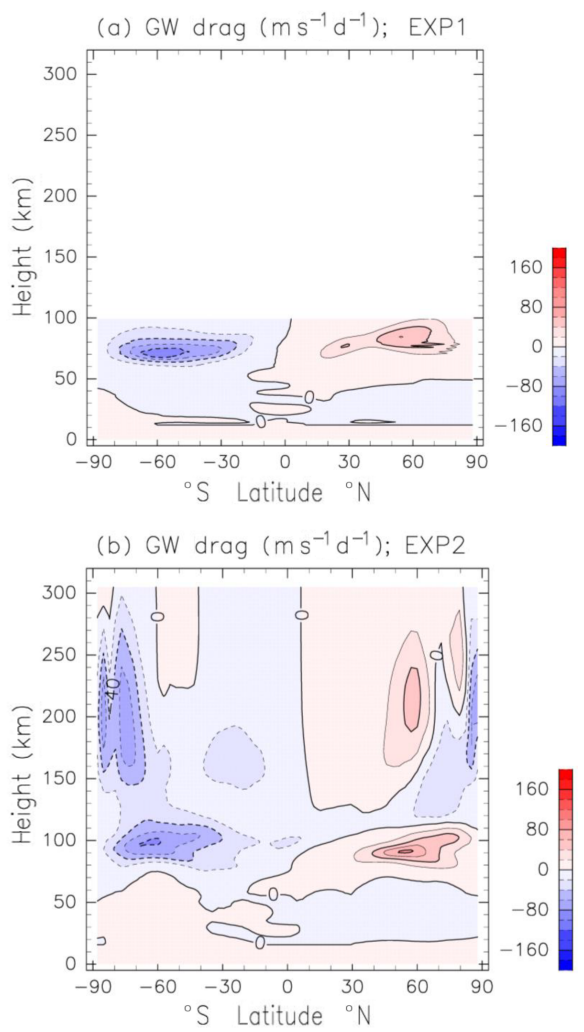

Figure 7. (a) Height-latitude section of the zonal mean of the zonal GW drag in June obtained by EXP1. Positive and negative values are eastward and westward acceleration, respectively. Units are meters per second per day. (b) As in (a) except for EXP2.

(Walterscheid and Hickey, 2012). Transient atmospheric processes can dramatically modulate penetration of GWs into the thermosphere. During minor warming, thermospheric GW activity can be enhanced significantly (e.g., Yiğit et al., 2014; Yiğit and Medvedev, 2016), while during major warmings it may encounter a decrease (Nayak and Yiğit, 2019). Here, we used a whole-atmosphere GCM incorporating a whole-atmosphere GW parameterization in order to the study the mean dynamical effects of GWs and their impact on the semidiurnal tides in the thermosphere.

Using the SABER measurement aboard the TIMED satellite, Pancheva and Mukhtarov (2011) investigated the behavior of the SW2 in the MLT. There, the typical observed peak values for the SW2 amplitudes are situated at low latitudes during the June solstice: $25-28 \mathrm{~K}$ at $15-30^{\circ} \mathrm{N}$ and $15-20 \mathrm{~K}$ at $15-25^{\circ} \mathrm{S}$. In our study, GCM simulations based on two different GW parameterizations yield different results for the SW2 tide. While the simulation with the standard Lindzen scheme overestimate the tidal amplitude, the one with the Yiğit scheme matches observations better. This can be explained by the additional GW drag in the thermosphere (i.e., additional physics) as accounted for by the Yiğit scheme,
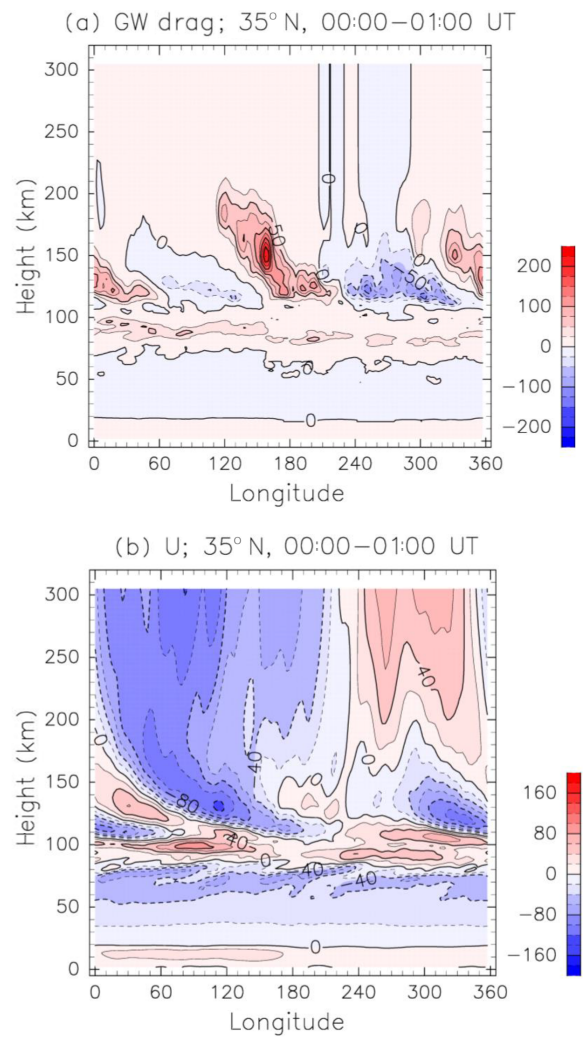

Figure 8. (a) Height-longitude section of the zonal GW drag at $35^{\circ} \mathrm{N}$ obtained by EXP2. Data are averaged between 00:00 and 01:00 UT in June. Units are meters per second per day. (b) As in (a) except for zonal-wind component. Units are meters per second.
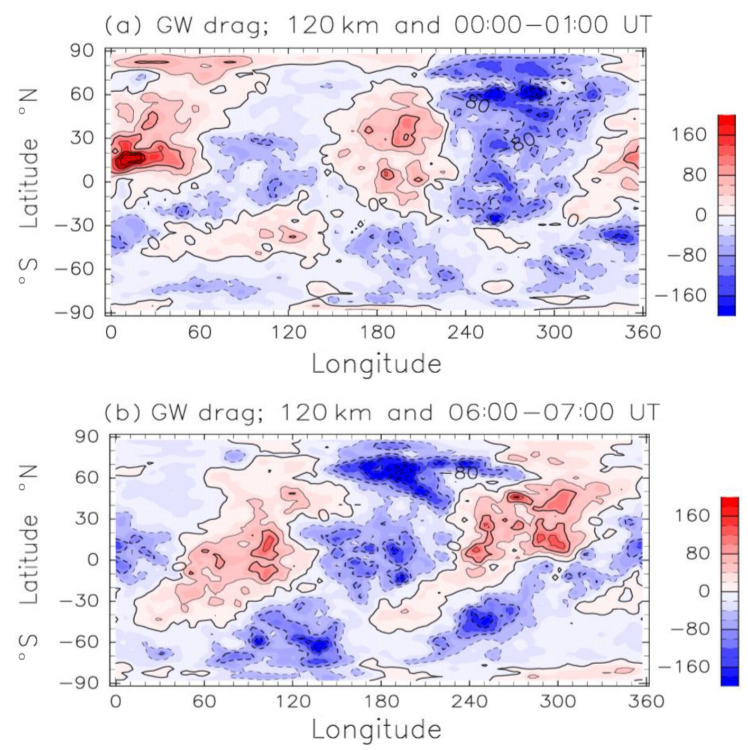

Figure 9. (a) Latitude-longitude section of the zonal GW drag at $120 \mathrm{~km}$ height in June. Data are averaged between 00:00 and 01:00 UT. Positive and negative values are eastward and westward acceleration, respectively. Units are meters per second per day. Contour intervals are $40 \mathrm{~m} \mathrm{~s}^{-1} \mathrm{~d}^{-1}$. (b) As in (a) except for the average between 06:00 and 07:00 UT. 

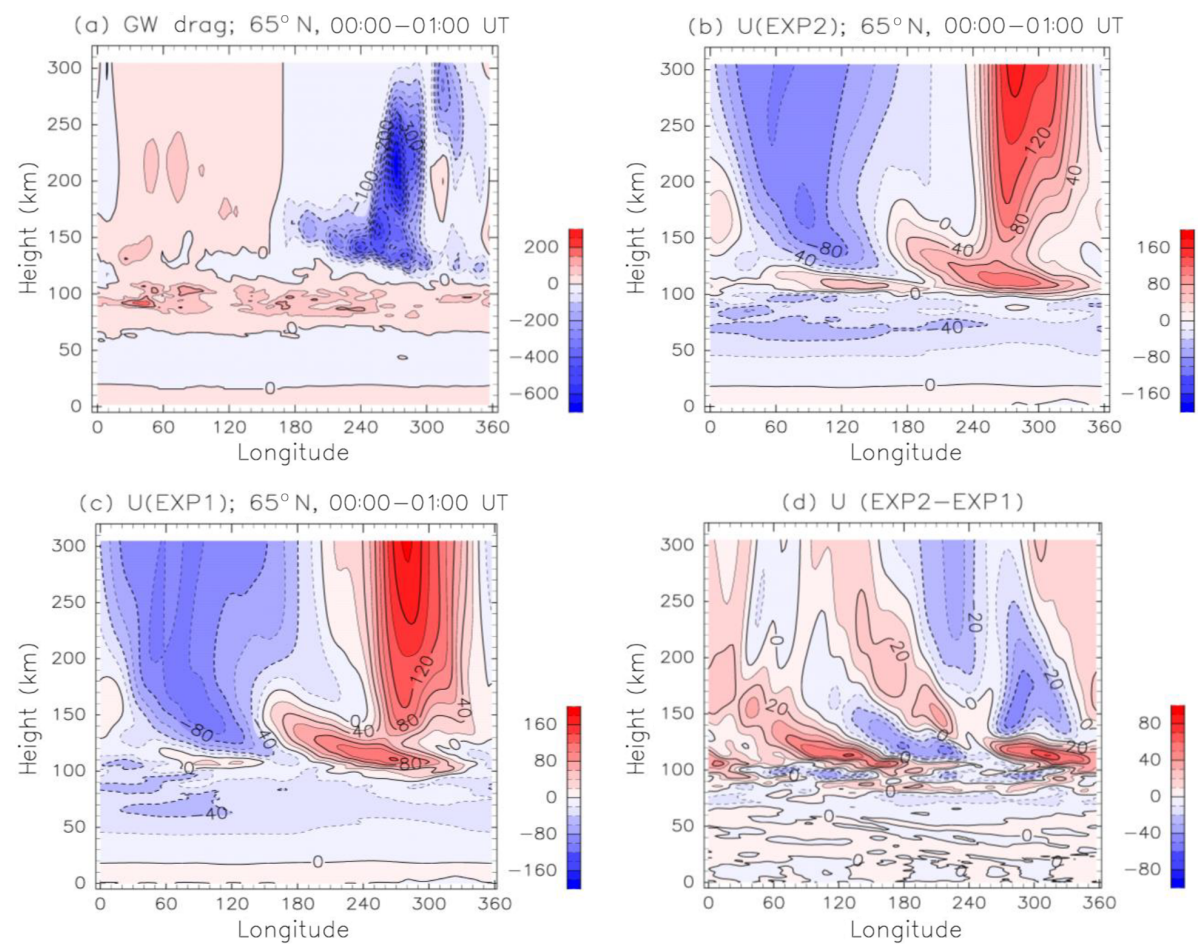

Figure 10. (a) Height-longitude section of the zonal GW drag at $65^{\circ} \mathrm{N}$ in June (EXP2). Data are averaged between 00:00 and 01:00 UT. Units are meters per second per day. Contour intervals are $50 \mathrm{~m} \mathrm{~s}^{-1} \mathrm{~d}^{-1}$. (b) As in (a) except for zonal-wind component obtained by EXP2. Units are meters per second. (c) As in (b) except for EXP1. (d) Difference of the zonal wind at $65^{\circ} \mathrm{N}$ between EXP1 and EXP2 (EXP2-EXP1). Units are meters per second. Contour intervals are $10 \mathrm{~m} \mathrm{~s}^{-1}$.

which attenuates the zonal-wind variation associated with the SW2.

Using the CHAMP and GRACE accelerometer measurements, Forbes et al. (2011) showed the SW2 amplitude in the upper thermosphere. The GCM without GW drag parameterization in the thermosphere fails to reproduce the observed SW2 in the upper thermosphere, whereas the GCM with the GW parameterization succeeds in reproducing the behavior of the observed SW2 in the upper thermosphere. This result also indicates the importance of the GW effects in the thermosphere.

There are substantial differences between the linear and the nonlinear schemes in the treatment of GW processes, as has been initially discussed in detail in the work by Yiğit et al. (2008). One major difference is that the linear scheme is based on the linear saturation principle, ignoring wave-wave interactions, while the Yiğit scheme takes into account not only nonlinear wave-wave interactions but also dissipation of GWs due to additional processes, such as ion drag, molecular viscosity, and thermal conduction, which are important dissipative processes in the thermosphere-ionosphere system. Any GCM that extends into the thermosphere, including a GW parameterization, must incorporate these effects on $\mathrm{GW}$ propagation. While the linear scheme assumes an artificial tuning factor for the GW drag, the nonlinear scheme does not require any artificial tuning parameters. However,
GW parameterizations are not devoid of limitations. They all assume a single-column approach and instantaneous response of the flow field to the upward-propagating waves.

The whole-atmosphere GCM uses an empirical ionospheric model. At high latitudes, the behavior of the ionosphere can substantially influence the thermospheric circulation. On the other hand, the background atmosphere is very important for the GW propagation and dissipation. A modeling framework with a self-consistent two-way coupled ionosphere-thermosphere system could provide a more realistic picture of ion-neutral coupling, and GW effects could be evaluated more precisely at high latitudes.

\section{Concluding remarks}

The GW parameterization developed by Yiğit et al. (2008) has been implemented in the Japanese Kyushu University whole-atmosphere GCM (Miyoshi and Fujiwara, 2008), and the impact of small-scale GWs on the migrating semidiurnal tide as well as the GW effects on the general circulation of the thermosphere have been studied. We obtained the following results.

1. The GW drag attenuates the magnitude of the zonalmean and diurnal-mean zonal wind in the thermosphere. 

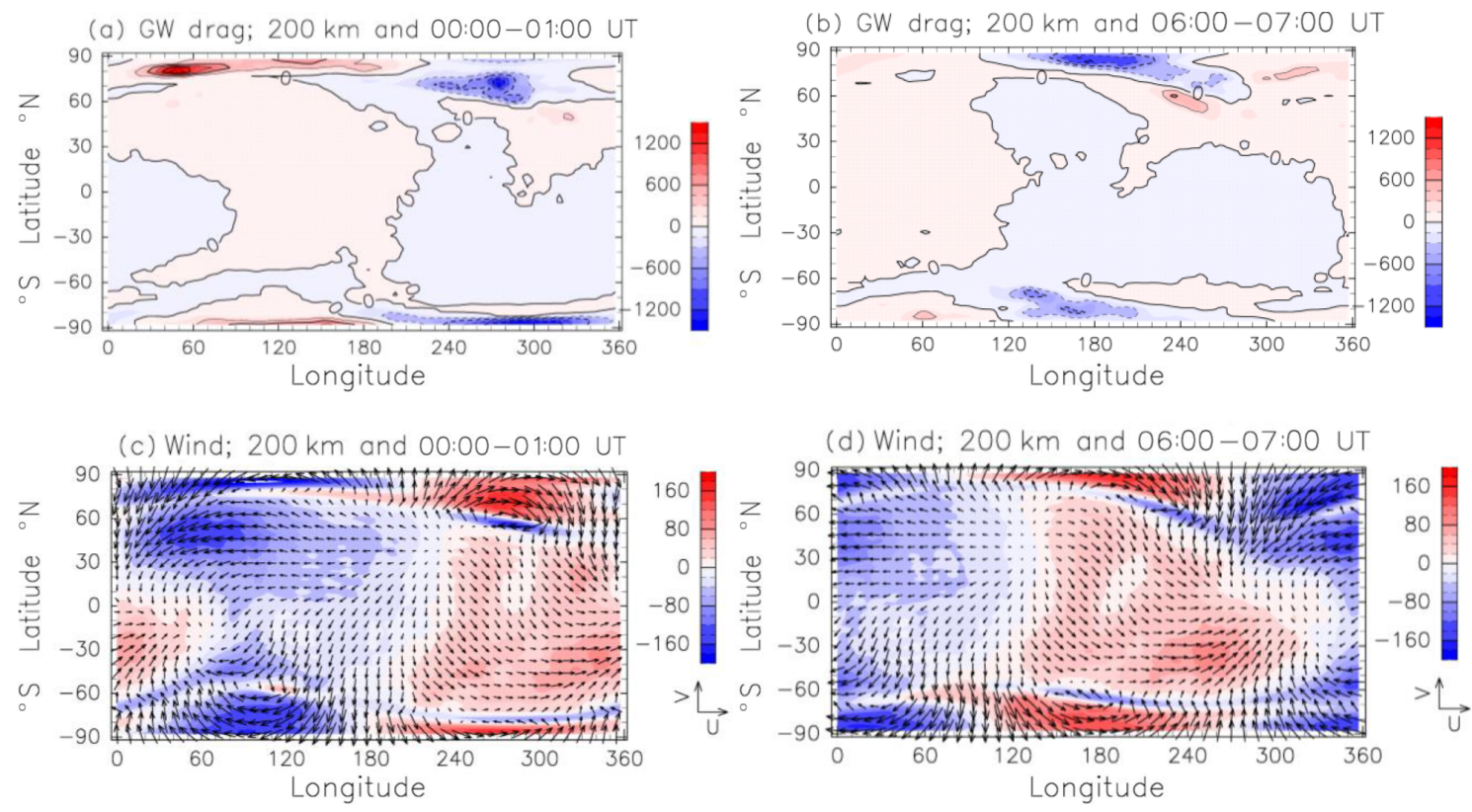

Figure 11. (a) Longitude-latitude section of the zonal GW drag at 200 km height in June. Data are averaged between 00:00 and 01:00 UT. Positive and negative values are eastward and westward acceleration, respectively. Units are meters per second per day. Contour intervals are $200 \mathrm{~m} \mathrm{~s}^{-1} \mathrm{~d}^{-1}$. (b) As in (a) except for the average between 06:00 and 07:00 UT. (c) Vectors indicate the global distribution of the horizontal wind at $200 \mathrm{~km}$ height obtained by EXP2. Data are averaged between 00:00 and 01:00 UT in June. The vectors on the right-hand side indicate the zonal wind and meridional winds with magnitudes of $200 \mathrm{~m} \mathrm{~s}^{-1}$. Color bars are the global distribution of the zonal-wind component at $200 \mathrm{~km}$ height. Data are averaged between 00:00 and 01:00 UT. (d) As in (c) except for the average between 06:00 and 07:00 UT.

The GW drag modifies the zonal-mean meridional and temperature distributions in the thermosphere.

2. The GW drag attenuates the SW2 amplitude in the lower thermosphere and modifies the latitudinal structure of the SW2 above a $150 \mathrm{~km}$ height. The GW drag also attenuates the TW3 amplitude in the thermosphere.

3. The GW drag in the lower thermosphere has zonal wavenumber 2 structure and has semidiurnal variation.

4. The GW drag above a $150 \mathrm{~km}$ height is enhanced in high latitudes. The maximum value sometimes exceeds $1000 \mathrm{~m} \mathrm{~s}^{-1} \mathrm{~d}^{-1}$. This means that the GW drag plays an important role in the momentum balance in high latitudes above a $150 \mathrm{~km}$ height.

The whole-atmosphere GCM used in this study uses an empirical ionosphere. Therefore, impacts of the GW drag on the ionospheric variability have not been investigated in this study. In the next step, implementation of GW drag parameterization in an atmosphere-ionosphere coupled model, such as GAIA (Jin et al., 2012), is strongly required. Using an atmosphere-ionosphere coupled model with GW drag, we will investigate impacts of the GW drag on the ionospheric variability.
Data availability. Upon request, the data used for the publication of this study are available from Yasunobu Miyoshi (y.miyoshi.527@m.kyushu-u.ac.jp).

Author contributions. YM performed the simulation and wrote a substantial portion of the paper. EY provided the whole-atmosphere GW parameterization scheme and significantly contributed to writing and discussion of results.

Competing interests. Erdal Yiğit is one of the editors of this special issue. The authors declare that they have no conflict of interest.

Special issue statement. This article is part of the special issue "Vertical coupling in the atmosphere-ionosphere system". It is a result of the 7th Vertical coupling workshop, Potsdam, Germany, 2-6 July 2018.

Acknowledgements. The GFD Dennou library was used to produce the figures. The numerical simulation was performed using the computer system at the Research Institute for Information Technology of Kyushu University and at the National Institute of Information and Communication Technology, Japan. Erdal Yiğit was partially funded by the National Science Foundation (NSF) grant AGS 1452137. 
Financial support. This research has been supported by the JSPS, Japan (grant no. 15H03733); the JSPS, Japan (grant no. 18H04447); and the National Science Foundation, USA (grant no. AGS 1452137).

Review statement. This paper was edited by Kathrin Baumgarten and reviewed by two anonymous referees.

\section{References}

Akmaev, R. A., Fuller-Rowell, T. J., Wu, F., Forbes, J. M., Zhang, X., Anghel, A. F., Iredell, M. D., Moorthi, S., and Juang, H.-M.: Tidal variability in the lower thermosphere: Comparison of Whole Atmosphere Model (WAM) simulations with observations from TIMED, Geophys. Res. Lett., 35, L03810, https://doi.org/10.1029/2007GL032584, 2008.

Chiu, Y. T.: An improved phenomenological model of ionospheric density, J. Atmos. Terr. Phys., 37, 1563-1570, 1975.

England, S. L., Dobbin, A., Harris, M. J., Arnold, N. F., and Aylward, A. D.: A study into the effects of gravity wave activity on the diurnal tide and airglow emissions in the equatorial mesosphere and lower thermosphere using the Coupled Middle Atmosphere and Thermosphere (CMAT) general circulation model, J. Atmos. Sol.-Terr. Phy., 68, 293-308, https://doi.org/10.1016/j.jastp.2005.05.006, 2006.

Forbes, J. M., Zhang, X., Palo, J., Russell, C., Mertens, J., and Mlynczak M.: Tidal variability in the ionospheric dynamo region, J. Geophys. Res., 113, A02310, https://doi.org/10.1029/2007JA012737, 2008.

Forbes, J. M., Zhang, X., Bruinsma, S., and Oberheide, J.: Sunsynchronous thermal tides in exosphere temperature from CHAMP and GRACE accelerometer measurements, J. Geophys. Res., 116, A11309, https://doi.org/10.1029/2011JA016855, 2011.

Fuller-Rowell, T. J. and Evans D. S.: Height-integrated Pedersen and Hall conductivity patterns inferred from the TIROS-NOAA satellite data, J. Geophys. Res., 92, 7606-7618, 1987.

Garcia, R. and Solomon, S.: The effect of breaking gravity waves on the dynamics and chemical composition of the mesosphere and lower thermosphere, J. Geophys. Res., 90, 3850-3868, 1985.

Gavrilov, N. M. and Kshevetskii S. P.: Dynamical and thermal effects of nonsteady nonlinear acoustic-gravity waves propagating from tropospheric sources to the upper atmosphere, Adv. Space Res., 56, 1833-1843, 2015.

Heale, C. J., Snively, J. B., Hickey, M. P., and Ali, C. J.: Thermospheric dissipation of upward propagating gravity wave packets, J. Geophys. Res., 119, 3857-3872, https://doi.org/10.1002/2013JA019387, 2014.

Hickey, M. P., Walterscheid, R. L., and Schubert, G.: Gravity wave heating and cooling of the thermosphere: Sensible heat flux and viscous flux of kinetic energy, J. Geophys. Res., 116, A12326, https://doi.org/10.1029/2011JA016792, 2011.

Jin, H., Miyoshi, Y., Fujiwara, H., and Shinagawa, H.: Electrodynamics of the formation of ionospheric wave number 4 longitudinal structure, J. Geophys. Res., 113, A09307, https://doi.org/10.1029/2008JA013301, 2008.
Jin, H., Miyoshi, Y., Pancheva, D., Mukhtarov, P., Fujiwara, H., and Shinagawa, H.: Response of migrating tides to the stratospheric sudden warming in 2009 and their effects on the ionosphere studied by a whole atmosphere-ionosphere model GAIA with COSMIC and TIMED/SABER observations, J. Geophys. Res., 117, A10323, https://doi.org/10.1029/2012JA017650, 2012.

Kobayashi, S., Ota, Y., Harada, Y., Ebita, A, Moriya, M., Onoda, H., Onogi, K., Kamahori, H., Kobayashi, C., Endo, H., Miyaoka, K., and Takahashi, K.: The JRA-55 Reanalysis, J. Meteorol. Soc. Jpn., 93, 5048, https://doi.org/10.2151/jmsj.2015-001, 2015.

Lindzen, R. S.: Turbulence and stress owing to gravity wave and tidal breakdown, J. Geophys. Res., 86, 9707-9714, 1981.

Liu, H.-L., McInerney, J. M., Santos, S., Lauritzen, P. H., Taylor, M. A., and Pedatella, N. M.: Gravity waves simulated by high-resolution Whole Atmosphere Community Climate Model, Geophys. Res. Lett., 41, 9106-9112, https://doi.org/10.1002/2014GL062468, 2014.

Lübken, F.-J., Berger, U., and Baumgarten, G.: On the anthropogenic impact on long-term evolution of noctilucent clouds, Geophys. Res. Lett., 45, 6681-6689, https://doi.org/10.1029/2018GL077719, 2018.

Matsuno, T.: A quasi one-dimensional model of the middle atmosphere circulation interacting with internal gravity waves, J. Meteorol. Soc. Jpn., 60, 215-226, 1982.

McFarlane, N. A.: The effect of orographically excited gravity wave drag on the general circulation of the lower stratosphere and troposphere, J. Atmos. Sci., 44, 1775-1800, 1987.

Medvedev A. S. and Klaassen, G. P.: Parameterization of gravity wave momentum deposition based on nonlinear wave interactions: basic formulation and sensitivity tests, J. Atmos. Sol.-Terr. Phy., 62, 1015-1033, https://doi.org/10.1016/S13646826(00)00067-5, 2000.

Medvedev, A. S., Yiğit, E., and Hartogh, P.: Ion friction and quantification of the geomagnetic influence on gravity wave propagation and dissipation in the thermosphereionosphere, J. Geophys. Res.-Space, 122, 12464-12475, https://doi.org/10.1002/2017JA024785, 2017.

Miyahara, S. and Forbes, J. M.: Interactions between gravity waves and the diurnal tide in the mesosphere and lower thermosphere, J. Meteorol. Socf Jpn., 69, 523-531, 1991.

Miyahara, S., Yoshida, Y., and Miyoshi, Y.: Dynamic coupling between the lower and upper atmosphere by tides and gravity waves, J. Atmos. Terr. Phys., 55, 1039-1053, 1993.

Miyoshi, Y.: Numerical simulation of the 5-day and 16-day waves in the mesopause region, Earth Planets Space, 51, 763-772, 1999.

Miyoshi, Y.: Temporal variation of nonmigrating diurnal tide and its relation with the moist convective activity, Geophys. Res. Lett., 33, L11815, https://doi.org/10.1029/2006GL026072, 2006.

Miyoshi, Y. and Fujiwara, H.: Day-to-day variations of migrating diurnal tide simulated by a GCM from the ground surface to the exobase, Geophys. Res. Lett., 30, 1789, https://doi.org/10.1029/2003GL017695, 2003.

Miyoshi, Y. and Fujiwara, H.: Gravity waves in the thermosphere simulated by a general circulation model, J. Geophys. Res., 113, D01101, https://doi.org/10.1029/2007JD008874, 2008.

Miyoshi, Y., Fujiwara, H., Forbes, J. M., and Bruinsma, S. L.: Solar terminator wave and its relation to the atmospheric tide, J. Geophys. Res., 114, A07303, https://doi.org/10.1029/2009JA014110, 2009. 
Miyoshi, Y., Fujiwara, H., Jin, H., and Shinagawa H.: A global view of gravity waves in the thermosphere simulated by a general circulation model, J. Geophys. Res.-Space, 119, 5807-5820, https://doi.org/10.1002/2014JA019848, 2014.

Miyoshi, Y., Fujiwara, H., Jin, H., and Shinagawa H.: Impacts of sudden stratospheric warming on general circulation of the thermosphere, J. Geophys. Res.-Space, 120, 10897-10912, https://doi.org/10.1002/2015JA021894, 2015.

Nayak, C. and Yiğit, E.: Variation of small-scale gravity wave activity in the ionosphere during the major sudden stratospheric warming event of 2009. J. Geophys. Res.-Space, 124, 470-488, https://doi.org/10.1029/2018JA026048, 2019.

Pancheva, D. and Mukhtarov, P.: Atmospheric tides and planetary waves: recent progress based on SABER/TIMED temperature measurements (2002-2007), Aeronomy of the Earth's Atmosphere and Ionosphere, Division II IAGA Special Sporon Book Series 2, https://doi.org/10.1007/978-94-007-0326-1_2, 2011.

Vadas, S. L. and Fritts, D. C.: Thermospheric responses to gravity waves arising from mesoscale convective complexes, J. Atmos. Sol.-Terr. Phy., 66, 781-804, 2004.

Vadas, S. L. and Fritts D. C.: Thermospheric responses to gravity waves: Influences of increasing viscosity and thermal diffusivity, J. Geophys. Res., 110, D15103, https://doi.org/10.1029/2004JD005574, 2005.

Walterscheid, R. L. and Hickey, M. P.: Gravity wave propagation in a diffusively separated gas: Effects on the total gas, J. Geophys. Res., 117, A05303, https://doi.org/10.1029/2011JA017451, 2012.

Yiğit, E. and Medvedev, A. S.: Heating and cooling of the thermosphere by internal gravity waves, Geophys. Res. Lett., 36, L14807, https://doi.org/10.1029/2009GL038507, 2009.

Yiğit, E. and Medvedev, A. S.: extending the parameterization of gravity waves into the thermosphere and modeling their effects, Climate and Weather of the Sun-Earth System (CAWSES), 467-480, https://doi.org/10.1007/978-94-0074348-9_25, Springer Press, the Netherlands, 2013.

Yiğit, E. and Medvedev, A. S.: Internal wave coupling processes in Earth's atmosphere, Adv. Space Res., 55, 983-1003, https://doi.org/10.1016/j.asr.2014.11.020, 2015.
Yiğit, E. and Medvedev, A. S.: Role of gravity waves in vertical coupling during sudden stratospheric warmings, Geosci. Lett., 3, 27, https://doi.org/10.1186/s40562-016-0056-1, 2016.

Yiğit, E. and Medvedev, A. S.: Influence of parameterized small-scale gravity waves on the migrating diurnal tide in Earth's thermosphere, J. Geophys. Res.-Space, 122, 4846-4864, https://doi.org/10.1002/2017JA024089, 2017.

Yiğit, E. and Ridley A. J.: Effects of high-latitude thermosphere heating at various scale sizes simulated by a nonhydrostatic global thermosphere-ionosphere model, J. Atmos. Sol-Terr. Phy., 73, 592-600, https://doi.org/10.1016/j.jastp.2010.12.003, 2011.

Yiğit, E., Aylward, A. D., and Medvede, A. S.: Parameterization of the effects overtically propagating gravity waves for thermosphere general circulation models: Sensitivity study, J. Geophys. Res., 113, D19106, https://doi.org/10.1029/2008JD010135, 2008.

Yiğit, E., Medvedev, A. S., Aylward, A. D., Hartogh, P., and Harris, M. J.: Modeling the effects of gravity wave momentum deposition on the general circulation above the turbopause, J. Geophys. Res., 114, D07101, https://doi.org/10.1029/2008JD011132, 2009.

Yiğit, E., Medvedev, A. S., Ridley, A. J., Aylward, A. D., Harris, M. J., Moldwin, M. B., and Hartogh, P.: Dynamical effects of internal gravity waves in the equinoctial thermosphere, J. Atmos. Sol-Terr. Phy., 90-91, 104-116, 2012.

Yiğit, E., Medvedev, A. S., England, S. L., and Immel, T. J.: Simulated variability of the high-latitude thermosphere induced by small-scale gravity waves during a sudden stratospheric warming, J. Geophys. Res.-Space, 119, 357-365, https://doi.org/10.1002/2013JA019283, 2014.

Yiğit, E., Medvedev, A. S., and Hartogh, P.: Influence of gravity waves on the climatology of high-altitude Martian carbon dioxide ice clouds, Ann. Geophys., 36, 1631-1646, https://doi.org/10.5194/angeo-36-1631-2018, 2018. 